\title{
GLOBALIZACIÓN, DESMODERNIZACIÓN Y EL RETORNO DE LOS MONSTRUOS*
}

\author{
Mary Louise Pratt \\ Silver professor of Spanish and Portuguese and \\ Professor of comparative literatura at New York University
}

\section{Resumo}

O principal objetivo deste ensaio é refletir sobre como o processo de globalização é interpretado e representado por distintos imaginários, tais como : públicos, oficiais, vernaculares e pelas zonas de exclusão.

\section{Pallavras-Chave}

Globalização • Neoliberalismo • Imaginários • Monstros

\section{Abstract}

The main focus of this essay is to discuss about the globalization process and how it's interpreted and represented by diferents imaginaries, such as publics, officials, vernaculars and the exclusions zones.

\section{Keywords}

Globalization • Neoliberalism • Imaginaries • Monsters

\footnotetext{
* Conferencia presentada en el Tercer Encuentro de Performance y Política, Universidad Católica, Lima, Perú, julio 2002. Agradezco a Elvira Maldonado por su ayuda como editora y traductora. El presente texto se hizo realidad gracias a los auspicios de una beca del Center for Advanced Study in the Behavioral Sciences (Centro para Estudios Avanzados en Ciencias del Comportamiento) de Stanford University 2000-2001, y debe mucho a conversaciones estimulantes con James Ferguson, Lisa Malkki y Jean Lave. Agradezco también a los colegas del Centro de Investigación y Estudios Superiores de Antropología Social (CIESASOccidente) en Guadalajara, México, por muchas sugerencias que enriquecieron este trabajo, y por el privilegio de pasar un año sabático con ellos. Los aportes de Gabriel Torres, María de la O. Castellanos, Reneé de la Torre, Mercedes González de la Rocha y Rossana Reguillo fueron de particular importancia en las reflexiones relacionadas con la globalización, la pauperización y sus dimensiones existenciales.
} 


\section{Introducción}

Las presentes reflexiones parten de un cierto escepticismo con relación al término globalización. Sospecho que, en muchas ocasiones, este término funciona como una etiqueta que carece de lo que los teóricos llaman poder explicativo. Lejos de ser una explicación, es un vocablo que, más bien, sustituye a la explicación - uno ve un Macdonalds en Lima y se dice "Ah, es la globalización." Se encuentra con una mujer zapoteca en Manhattan o se compra una mochila hecha en Macau o Madagascar, y se dice lo mismo. El término globalización suprime el entendimiento, y hasta el deseo de entendimiento. En ese sentido, la globalización funciona a menudo como una especie de falso protagonista que impide una interrogación más aguda sobre los procesos que han estado reorganizando las prácticas y los significados durante los últimos 25 años. Nos faltan vocabularios más exigentes, más explicativos.

Indudablemente tales vocabularios incluirían el término neoliberalismo. Este parece ser un protagonista menos falso, en la medida en que refiere directamente a la nueva etapa que vivimos, de capitalismo predatorio. Al mismo tiempo, el neoliberalismo tampoco lo explica todo, o mejor dicho, es importante no permitir que lo explique todo. Cederle ese poder significaría reducir todo a una sola cosa - gesto siempre posible en la medida en que uno esté dispuesto a descartar, desvalorizar, o simplemente no ver las contraindicaciones. Gesto también atractivo, ya que permite ver el mundo de manera coherente y comprensible - pero al costo de aceptar el desespero como la única respuesta razonable. Darle un monopolio interpretativo al capital sólo sirve para reproducir el monopolismo capitalista, cederle el poder totalizante que busca. Aún en el corazón mismo de nuestras sociedades capitalistas y consumistas, existen muchas prácticas, relaciones, instituciones y formas de subjetividad que no son regidas por las leyes del capital y del consumo. Aprendemos a no valorizar, e incluso a no ver estos fenómenos, precisamente porque no caben dentro de los grandes paradigmas teóricos que facilitan nuestro entendimiento del mundo. Dada la carencia de principios y métodos para entender las dimensiones no capitalistas de las sociedades capitalistas, éstas manifestaciones no se hacen visibles, o aparecen como triviales. Son lecciones, sin embargo, que se pueden desaprender.

También propongo reflexionar acerca de una dimensión sistemáticamente descontrolada y contradictoria del proyecto neoliberal, que es la siguiente : en la medida en que nos polariza económicamente, concentrando el poder de consumo en un número de manos cada vez más reducido, el neoliberalismo crea 
inmensas zonas de exclusión donde las personas son, y saben que son, completamente superfluas al orden histórico global. A través del planeta enormes sectores de la humanidad organizada viven con la conciencia de ser redundantes e innecesarios al orden económico, de haber sido expulsados de todas las narrativas de un futuro colectivo o individual que el neoliberalismo ofrece, y sin esperanzas de entrar (o volver a entrar) en el orden de producción y consumo. No sólo el progreso sino también la idea del progreso ha dejado, y !con qué rapidez!, de funcionar como un mito colectivo y global. En ese sentido, la globalización ha sido acompañada por una desglobalización, por procesos de aislamiento. Los mercados se abren y crecen, pero también se cierran y se concentran.

En estas zonas de exclusión, que se extienden sobre grandes partes de nuestro hemisferio, la vida se tiene que llevar y se está llevando de otras maneras. Se generan prácticas vitales distintas de las que ofrecen la modernidad y el consumo, otros modos de integración social y de formación subjetiva, otros valores, conocimientos, placeres, significados, esperanzas y formas de trascendencia. Es decir, el neoliberalismo crea vastos dramas humanos que él mismo no tiene la más mínima capacidad de entender. Esta me parece una situación muy interesante, imprevisible y llena de posibilidades. En las páginas que siguen, propongo reflexionar un poco sobre las formas en que los procesos subsumidos por el término globalización son representados e interpretados por los distintos imaginarios - públicos, oficiales y vernaculares. Al final, retomo el tema de las zonas de exclusión y los procesos de lo que propongo llamar la desmodernización.

\section{Un archivo reciclado}

Todo acercamiento a nuestro momento histórico reconoce la importancia de las profundas alteraciones y aceleraciones de los patrones de movilidad humana, siendo sus manifestaciones más evidentes la migración y el turismo masivos. Actualmente, el turismo constituye la industria más grande del mundo después del narcotráfico. Por su parte, la migración ha producido, entre otras cosas, una inversión del momentum expansionista de la modernidad desde un centro europeo y norteamericano hacia afuera. En los últimos 40 años, la trayectoria ha sido al revés : los sujetos ex-coloniales se desplazan, con una frecuencia cada vez mayor, hacia las metrópolis. Leemos que el quince por ciento de la población de Guyana vive en Nueva York y la mitad de la población de Surinam reside en Holanda. Según el censo del año 2000, en Estados Unidos uno de cada diez habitantes nació en otro país y uno de cada diez es 
hijo de alguien nacido en otro país (No se sabe cuántos de los 9 a 15 millones de indocumentados están incluidos en estas cifras). En California, la lengua materna de más de la mitad de los niños que entran a la escuela es diferente al inglés. En casi todas las ciudades europeas y estadounidenses, y en las asiáticas también, existen comunidades diaspóricas procedentes de muchas partes del globo, a menudo de antiguas colonias de los países mismos, y éstas han tenido un impacto en todos los aspectos de la vida institucional y cotidiana.

La metrópoli, aunque necesitada de esta diáspora revertida, no siempre se muestra acogedora. En mi condición de analista de la literatura de viajes, me resultó fascinante reconocer en la década de los 90 un reciclaje muy particular de los archivos de viaje de los siglos XVII y XVIII. Me refiero a los cuentos dramáticos de sufrimiento y supervivencia, de monstruos y de maravillas que, 300 años atrás, llegaban a Europa procedentes de las lejanas costas de África, de los mares del sur, de las Américas. En la última década del siglo XX, el mismo tipo de relato empezó a reaparecer diariamente, pero esta vez en las costas mismas de la metrópoli. Los relatos de naufragios, por ejemplo, reaparecieron en nuestros periódicos, llegando no de Tierra del Fuego, como antes, sino de la costa sur de Francia, donde 900 kurdos encallaron hace dos años, o desde Italia, destino de barcos llenos de Albaníes y Sudaneses. Antes, los relatos de polizones ("stowaways") nos hablaban de chicos europeos que se escondían en buques con destino hacia los mares del sur. Hoy, cuentan de jóvenes africanos que aparecen muertos de frío bajo la escotilla de los aviones que aterrizan en los aeropuertos europeos, ${ }^{1}$ o de familias búlgaras escondidas bajo los trenes que cruzan el túnel de la Mancha. El relato del náufrago fue revivido notablemente hace un par de años en las playas de Florida, con la historia del niño cubano Elián González, único sobreviviente de una precaria embarcación que zarpó desde la isla. No fueron los polinesios, sino los floridianos, (¡los electores de Bush!) quienes decidieron que se trataba de una reencarnación del Niño Jesús que se había salvado por la ayuda de los delfines.

Otra vez vivimos en un mundo de bandidos y piratas, ahora bajo la forma de coyotes y polleros que trabajan en las fronteras de todo el planeta. Los cuentos

\footnotetext{
${ }^{1}$ Ver FERGUSON, James. Expectations of modernity: Myths and meanings of urban life on the Zambian copperbelt. Berkeley: University of California Press, 1999.
} 
de supervivencia nos llegan ya no del Sahara, sino del desierto de Arizona, como fue el caso del verano del 2000, cuando un bebé fue milagrosamente rescatado de los brazos de su madre muerta, una joven salvadoreña que intentaba cruzar la frontera para entrar a los Estados Unidos. No fueron beduinos nómadas los que salvaron al niño sino la infame patrulla fronteriza (Border Patrol), cuya función es perseguir a los inmigrantes indocumentados. Las narrativas de cautiverio, género tan celebrado en los siglos XVI-XIX, resurgen hoy en día protagonizadas por trabajadoras explotadas en las casas de lujo de Beverly Hills o en las fábricas y los burdeles de San Francisco, Milán, y México. La asfixiante pesadilla de la embarcación de esclavos, tema candente del movimiento abolicionista en el siglo XVIII, volvió a hacerse presente en 1999 en el puerto de San Francisco, cuando 18 trabajadores chinos enloquecidos por terror y padecimiento salieron de un contenedor de carga en el fondo de las bodegas de un carguero en el que murieron siete de sus compañeros. En la primavera siguiente, Inglaterra fue sacudida por la historia de otros 43 chinos que perecieron envenenados por monóxido de carbono en la parte trasera de un camión en el que intentaban cruzar la frontera, procedentes de Holanda. Al momento de escribir este texto, el periódico informa de un camión que llega a Texas con los cadáveres de dos mexicanos sofocados por el calor, y unos veinte sobrevivientes, apenas vivos.

En abril del 2001 brotaron de nuevo historias de linchamientos de negros, pero ya no se trataba del viejo Sur de EE.UU., sino de la ultra moderna España. La esclavitud misma salió de su sepulcro. En Sudán se rescataron centenares de huérfanos Dinka esclavizados en el trabajo agrícola, en empresas que enfrentaban bajas dramáticas en los precios internacionales para sus productos. En Abidjan, según informó el London Daily Telegraph en el 2000, las niñas se vendían por cinco libras. "Sentí que asistía a un espectáculo del siglo XIX," afirma el reportero. Frente a esta vuelta al pasado, el abolicionismo se sacudió el polvo, encabezado, como hace 150 años, por la Anti-Slavery Society de Londres. Seguramente, no es este el escenario que imaginábamos para el inicio del nuevo milenio.

En los años 90 las fronteras de las metrópolis se convirtieron en teatros de aventurismo y sufrimiento, de muertes y supervivencias. Como sucedió con la literatura de viajes de los siglos XVII y XVIII, los relatos públicos que circulan ponen en escena un nuevo orden planetario, un nuevo orden imperial. La función de los relatos es la de crear los sujetos de ese nuevo orden, es decir, de crearnos a nosotros mismos como sus sujetos, de enseñar a cada uno su lugar. 
Este reciclaje contemporáneo de los archivos de viaje de los siglos XVII y XVIII hace resurgir los viejos temas, pero con una importante inversión de términos. Los géneros anteriores -los cuentos de cautiverio, de naufragios, de polizones, de piratas- eran narrados por los sobrevivientes, aquellos que, providencialmente (término clave en el vocabulario dieciochesco), lograron vivir para contar la historia. Por definición, siempre había un desenlace feliz que afirmaba la viabilidad de un sujeto emergente metropolitano global, a menudo imperial. El protagonista de las versiones actuales, en la mayoría de los casos, es un muerto, aquel que no logró sobrevivir, el que no llegó, el que nunca regresó. Motivados por otro tipo de deseo, los relatos de hoy ponen en escena dramas no de partida y regreso, sino de negación, exclusión y fracaso.

Desde el punto de vista narrativo, sospecho que, entre otras cosas, esta letanía de cadáveres ha sido una respuesta al carácter netamente utópico de los discursos oficiales sobre la globalización. A principios de la década del 90, el discurso académico, a través del espectrum ideológico, demostraba claramente este carácter utópico. En una de las primeras antologías metropolitanas ${ }^{2}$ los autores hablaban por ejemplo de un nuevo "ideal cosmopolita", de un "sueño de ecumenismo secular", de "la cristalización del mundo entero como un solo espacio" y de "la emergencia de una condición humana global"; una "cultura global" que es una "organización de la diversidad". "La humanidad", afirmó Ulf Hannerz en ese momento apasionante, "se ha despedido por fin de un mundo que, con una cierta credibilidad, podía verse como un mosaico cultural”. Hoy es difícil no percibir en estas apasionadas afirmaciones una narrativa imperial revisada, nuevamente inocente. El economista John Kenneth Galbraith, crítico mordaz, fue más claro al afirmar : "La globalización no es un concepto serio. Lo inventamos nosotros los norteamericanos para disfrazar nuestro programa de intervención económica en otros países."

\section{La fantasía del flujo}

En sus inicios, el discurso oficial sobre la globalización estableció su metáfora preferida, una metáfora de movilidad e inocencia que todavía impregna

\footnotetext{
${ }^{2}$ Ver FEATHERSTON, Mike. Global culture: Nationalism, globalization and modernity. London: Sage, 1990.
} 
muchos diálogos. La metáfora es el flujo : se imagina un planeta atravesado por flujos continuos, multidireccionales, de personas, objetos, dinero, información, lenguas, ideas, arte, imágenes. Desde lo "local" la idea es interceptar el flujo, a través de una planta de ensamblaje, una atracción turística, trabajadores enviados al exterior, una antena parabólica, una caja de sonido, un CD bajado de internet. Pero los trabajadores chinos que se asfixiaron no estaban fluyendo, estaban atrapados. El Río Bravo fluye, más no así los jóvenes que se ahogan intentando cruzarlo. Como nos lo recuerda la socióloga brasileña Teresa Caldeira, los ricos tampoco fluyen. ${ }^{3}$ Se encierran en condominios amurallados y vigilados; y cuando viajan buscan refugio en enclaves turísticos diseñados para dar la ilusión del lugar (Hasta el Papa, en un discurso el día del Turismo Internacional del año 2001 condenó la proliferación de lujosos resorts alejados totalmente de las sociedades que los rodean). Vale la pena detenernos un momento en esta metáfora del flujo, que es clave al sentido común de la globalización, para señalar las confusiones y evasiones que contiene.

1. La metáfora del flujo no distingue entre un tipo de movimiento y otro - no diferencia, por ejemplo, entre el desplazamiento de empleadas domésticas de las Filipinas al Medio Oriente y el movimiento de turistas del sexo desde Europa o Japón hacia Tailandia o Cuba. Pero, a pesar de usar los mismos aparatos aéreos, son movimientos muy distintos. Los turistas regresan a sus países de origen, pero las empleadas, con frecuencia, no pueden regresar porque sus hogares de origen dependen de sus ingresos. Su dinero fluye porque ellas no.

2. La metáfora del flujo neutraliza la cuestión de la direccionalidad. La serie televisiva "Dallas" es vista en África del Sur, pero los nuevos programas multirraciales y multilingües de Sudáfrica no llegan a las Américas. La mitad de la energía hidroeléctrica de México fluye desde Chiapas, en donde un alto porcentaje de los hogares carece de corriente eléctrica. El dinero, según me han dicho, cambia de manos 100 veces más a menudo que las mercancías, pero ese flujo, al fin de cuentas, tiene una dirección : a principios del 2001 Kofi Anan anunció que, después de considerar todas las di-

\footnotetext{
${ }^{3}$ Ver CALDEIRA, Teresa. City of walls: Crime, segregation and citizenship in São Paulo, Berkeley: University of California Press, 2001.
} 
versas formas de intercambio económico mundial, se pudo determinar que hubo un flujo de $\$ 450$ billones de dólares desde los países pobres hacia los ricos, tres cuartos de esta suma a los Estados Unidos. Para poner esto en perspectiva : ese mismo año, el presupuesto total de ayuda externa de los Estados Unidos sólo fue de \$22 billones de dólares, suma absurdamente mezquina equivalente a una fracción de los intereses que Argentina pagó sobre su deuda con los Estados Unidos. Los pagos de deudas con los países ricos actualmente consumen la mitad del presupuesto nacional del Ecuador, lo que explica el "flujo" hacia el exterior de un 14\% de la población de este país en los últimos cuatro años.

3. Como toda construcción ideológica, el "flujo" naturaliza. Las consecuencias principales son tres :

(a) Hace invisibles las políticas estatales, los acuerdos transnacionales, las instituciones y colaboraciones que crean las posibilidades e imposibilidades de movimiento. La difusión de las películas de Hollywood en todo el planeta, por ejemplo, no es un flujo natural de la cultura. Se trata de un negocio cuyo objeto es, en tanto que asunto comercial, acabar con la producción de cine en las otras naciones por medio de arreglos impuestos en los países pobres por los países ricos. ¿Es esta la nueva ecumene?

(b) El concepto de flujo anula la intervención y la intencionalidad humanas - la "agencia". Fluir es un verbo intransitivo - las cosas fluyen porque sí. Describir el dinero como algo que fluye oscurece el hecho de que es enviado y recibido de manera intencional de una persona a otra. Las personas que "fluyen" son aquellas que han tomado decisiones de ir o de regresar, de arriesgarse, emanciparse, o que han sido enviadas o reclamadas por otros como parte de estrategias pensadas, aunque a veces desesperadas. Al hacer invisible la intervención humana, el flujo saca de juego la dimensión existencial de las movilidades, la cuestión de cómo se está viviendo la globalización.

(c) El flujo sugiere, de forma perversa, un proceso que responde a las leyes naturales de gravedad. Los flujos automáticamente alcanzan un tranquilo equilibrio horizontal - así el mercado es pensado como naturalmente nivelador, como algo inherentemente democratizador. Pero, tal como la crítica de los últimos años ha puesto en evidencia, el neoliberalismo es ver- 
ticalizante, y su verticalidad no tiene límites de gravedad. La riqueza se va concentrando mientras la pauperización prolifera, y la cima y el fondo parecen desaparecer ante nuestros ojos. ¿Hasta qué nivel de riqueza personal puede llegar un individuo? ¿Hasta que profundidad puede llegar la pauperización masiva? Los estadistas dicen que el poder adquisitivo de la clase trabajadora en México es hoy un séptimo de lo que era en 1970, y los salarios son la mitad de lo que eran en 1980. Al menos un tercio de la población no tiene prácticamente nada; físicamente los cuerpos humanos en México son más pequeños en promedio de lo que eran hace 30 años. Y México es un rico país pobre. Los países ricos-ricos no han sido inmunes a la verticalización. Lo escuchamos una y otra vez : en los Estados Unidos el $40 \%$ de la población más pobre controla el $0.2 \%$ de la riqueza nacional, mientras el $10 \%$ más rico controla el $71 \%$. Es difícil no ver en el asalto a las torres gemelas un asalto a esta verticalización.

El "flujo" ejemplifica el lenguaje oficial, legitimador, de la globalización. Es un término con connotación positiva que opera desconectado de cualquier dimensión ética. El resultado es un lenguaje sin cima ni fondo. Un lenguaje que permite, por ejemplo, que la duplicación de las horas de trabajo, la explotación de los niños, la disminución de la comida y el infanticidio se califiquen como "coping strategies"; 4 o que cualquier forma o grado de pauperización se denomine "economía informal"; o que cualquier interacción, por desigual que sea, pueda ser descrita como un "intercambio."

\section{La vuelta de los monstruos}

En la literatura, al menos en las obras de ficción latinoamericanas de la última década, este mundo predatorio se hace presente precisamente por el opuesto del flujo. Proliferan narrativas de supervivientes aislados, tratando de crear esferas de acción significativas en espacios interiores claustrofóbicos, a los que se han retirado tratando de escapar de un mundo social que se ha convertido en un holocausto; y relatos de delincuencia violenta en los que la ausencia

\footnotetext{
${ }^{4}$ Ver GONZÁLEZ DE LA ROCHA, Mercedes. Private adjustments: Household responses to the erosion of work. UN Bureau for Development Policy, Conference Paper Series, 2000.
} 
de un futuro significa que nadie tiene nada que perder. En la cultura vernácula este hecho se registra del mismo modo en el que se hizo en los imperios anteriores : por la aparición de lo monstruoso.

A mediados de los 90, siguiendo la ruta del NAFTA, México y el Caribe fueron testigos de la aparición del chupacabras, una criatura alada de aproximadamente un metro de estatura, parecida a un murciélago, que salía en las noches y atacaba los corrales de las cabras en las regiones rurales de México. En los periódicos se publicaron fotos de corrales regados de cabras muertas y de mujeres con heridas en el cuello; dibujos del monstruo aparecieron primero en los periódicos y luego en las camisetas; los inevitables corridos también hicieron su aparición y el chupacabras llegó a aparecer en la serie televisiva de ficción 'Expedientes- $X$ '. Los detalles en estos relatos suelen ser significativos. Los orígenes del chupacabras, se contaba, estaban en un fallido experimento de ingeniería genética en un laboratorio secreto de una base militar estadounidense en Puerto Rico. La historia del chupacabras sintetizaba el asalto a la vida rural y la agricultura, patrocinado por el acuerdo NAFTA de 1994. Los ejidos fueron privatizados. La agricultura de subsistencia se declaraba en vía de desaparición; las cabras y el maíz iban a ser reemplazados por kiwis y brócolis. Los campesinos se vieron sujetos a enormes presiones para que utilizaran variedades genéticamente trabajadas para poder competir. Era evidente que el negocio de la agricultura de los Estados Unidos iba a chupar la sangre de los campesinos mexicanos minifundistas. ¿Por qué las cabras? El monstruo tenía como objetivo de ataque a las relaciones intensas entre las personas y los animales, relaciones que son el corazón mismo de la vida rural. En la zona rural mexicana la 'birria', preparación especial del cabrito, es la comida ritual de las bodas, locus de la reproducción social.

En la zona andina de Perú y Bolivia la era neoliberal fue demarcada por nuevas apariciones del pishtako, monstruo cuya leyenda se originó en los Andes en el siglo XVI en el contexto de la invasión española. El pishtako usaba polvos mágicos para dormir a las personas y les chupaba la grasa de sus cuerpos. No debe sorprendernos que el pishtako se manifestara a veces vistiendo una túnica similar a la de los frailes españoles. A finales de los 80, según Nathan Wachtel, el pishtako hizo una serie de apariciones en los Andes en respuesta a la acción depredadora del neoliberalismo ${ }^{5}$. En esta ocasión, chupaba la grasa

\footnotetext{
${ }^{5}$ WACHTEL, Nathan. Gods and vampires: Return to Chipaya. Chicago: University of Chicago Press, 1994.
} 
humana para exportarla a los Estados Unidos en donde, se decía, se vendía para la lubricación de maquinarias -autos, aviones, computadores. Los antropólogos reportaron una ola de pánico en 1987 cuando se difundió la noticia de que llegaba a Ayacucho un equipo de cinco mil pishtakos, vestidos con batas de laboratorio, con el objeto de recolectar grasa humana para venderla y pagar la deuda nacional del Perú. A pesar de su exclusión económica y política, los andinos no estaban fuera del circuito. La imagen representaba con una exactitud impresionante la naturaleza de las fuerzas que estaban ejerciendo presión sobre ellos.

Para evitar una lectura excesivamente mítica del fenómeno del pishtako, sólo es necesario pensar en su relación con la práctica metropolitana de la liposucción. ¿Por qué no explotar la notoria obesidad norteamericana para pagar la deuda externa del Perú? Es que, pensándolo bien, la grasa norteamericana ES la deuda del Perú, las exportaciones baratas convertidas en hiperconsumo en el norte.

Otra aparición de lo monstruoso en el imaginario vernáculo de la época neoliberal son las miles de historias relacionadas con el robo de órganos humanos. Desde la década de 1980 estas historias se han vuelto poderosamente significativas en lugares en los que la integridad y la supervivencia de las comunidades se han visto amenazadas. A mediados de los 90 estos relatos se habían propagado en tal escala que la Agencia de Información de los Estados Unidos (USAID United States Agency for International Development) montó una página web para desmentirlas. Una versión muy común es la del robo del riñón. En su variante más popular nos habla de un hombre que es seducido en un bar por una mujer muy atractiva con la que pasa la noche en un hotel. Al despertarse al día siguiente se encuentra solo, lleno de dolores, y con una incisión en el abdomen. Se da cuenta que lo han drogado para sacarle el riñón y venderlo en el exterior. El relato tiene muchas variantes, pero son asombrosas su frecuencia y consistencia, desde la India hasta Guatemala. De nuevo, desde una cosmovisión empapada de miedo y vulnerabilidad, los relatos de órganos robados registran las transformaciones del orden global de modo bastante preciso, particularmente en lo que se refiere a las nuevas modalidades de producción industrial que para el ensamblaje del producto final utilizan partes procedentes de todos los rincones del mundo. Los cuerpos de los pobres se convierten en productores de piezas a ser exportadas e insertadas en cuerpos enfermos, pero ricos, de otros países. Las comunidades están fragmentadas, partes de ellas han debido ser vendidas al exterior e instaladas en las entrañas de la bestia. ¿Son estas realidades las que han originado en épocas recientes el término "pos-humano"? 
En los Estados Unidos el cine y la televisión son los escenarios para la reemergencia de lo monstruoso. El ejemplo sobresaliente es la serie de ficción "Expedientes-X", que recién completó su novena (y última) temporada televisiva y donde todos los horrores mencionados arriba han hecho su aparición. ${ }^{6}$

\section{Getting it together}

Estas apariciones de lo monstruoso expresan los asaltos a los cuerpos, a la integridad individual y comunitaria que caracterizan el momento actual. La integridad individual y colectiva no son funcionales para el capitalismo actual que, como señalan los economistas, trabaja a base de una flexibilidad errante : la maquila armada hace un año en El Salvador en dos meses se traslada a Indonesia. Las historias de lo monstruoso alegorizan de manera muy exacta las fuerzas desagregadoras del neoliberalismo voraz y predatorio. Sin embargo, como sugerí al principio, es importante no dar un monopolio interpretativo a estas fuerzas. También estamos rodeados de narrativas y procesos de reensamblaje, de integración, recuperación, afirmación de pertenencias radicadas en lugares y en cosmos. Son procesos que nuestros imaginarios hegemónicos fácilmente descartan. Ofrezco algunos ejemplos, entre muchos que se podrían citar.

En gestos simultáneamente materiales y simbólicos, los pueblos indígenas del mundo están encabezando procesos de recuperación de órganos, huesos, restos y artefactos sagrados robados. Los casos son numerosísimos. En 1998 estas demandas de recuperación se habían vuelto tan comunes que en los Estados Unidos se aprobó una Ley de Repatriación. En EE.UU. un caso destacado ha sido la recuperación en el año 2000 del cerebro de Ishii, último sobreviviente de una tribu californiana. La búsqueda iniciada por una tribu vecina dio con el cerebro conservado en una bodega del Instituto Smithsonian en Washington. Los buscadores de Ishii seguían pistas abiertas en 1993 por los descendientes de un grupo de nativos Groenlandeses llevados a Nueva York hace un siglo por el antropólogo Franz Boas. Los descendientes reclamaron los huesos de sus antepasados, e incluso un representante viajó a pie hasta Nueva York para recuperarlos. En el mismo año la comunidad de Coruma, en Boli-

\footnotetext{
${ }^{6}$ Para una domesticación del tema, ver también la película más reciente de Clint Eastwood, "Blood Work".
} 
via, recuperó sus textiles sagrados de una galería californiana. Semanas atrás, los restos del cacique charrúa Vainaca Perú fueron regresados a Uruguay desde Francia, y desde Inglaterra los de una famosa representante de los Bushmen regresaron a Botswana.

Los migrantes del mundo también están encabezando procesos de integración y reensamblaje por medio de procesos de intensa y continua improvisación. Como sabemos, a través de todo el planeta se están desarrollando nuevas formas de identidad, de pertenencia y de ciudadanía capaces de responder al momentum desagregador de la migración. Los pueblos de México y de Centroamérica se duplican, estableciendo comunidades satélites en los Estados Unidos, desde las cuales las personas, los bienes, el dinero y las prácticas culturales van y vienen continuamente. Como lo mostró el estudio pionero de Roger Rouse, parte de Redwood City, California, es un suburbio de Apatzingán, Michoacán; ${ }^{7}$ el antropólogo guatemalteco Víctor Montejo afirma que en Florida hay comunidades tzotzuhil-hablantes que ocupan edificios de apartamentos que han reorganizado según las relaciones espacio-vitales mesoamericanas. Los mixteco de Oaxaca tienen ahora una red transnacional que va desde Puerto Escondido hasta Anchorage y desde Fresno hasta New Jersey. Para acomodarse a las necesidades de sus poblaciones migrantes, los pueblos reprograman y rediseñan las fiestas locales (patrón que privilegia nuevamente los calendarios religiosos frente a las fiestas nacionales). Los mismos migrantes negocian nuevas formas de participación, dentro de su estatus de migrantes. Todos los años en los meses de junio y julio, los vuelos de Mexicana de Aviación que salen del aeropuerto de San José, California, llevan cada uno a una docena de niños enviados a pasar el verano con sus abuelos en los ranchos y en los pueblos de Jalisco y Michoacán. Abundan los ejemplos de improvisación y ajuste destinados a mantener la integración y la continuidad a través de las distancias impuestas por la migración.

Las vírgenes y los santos no dejan de participar en los nuevos procesos, adoptando nuevas funciones móviles e integradoras. En México, señala la antropóloga mexicana Renée de la Torre, la Virgen de Guadalupe ha empezado a aparecer en lugares de tránsito como los aeropuertos o los puentes de las ca-

${ }^{7}$ ROUSE, Roger. Mexican migration and the social space of postmodernism. In : Diaspora $1: 1,1991$, p. $15-30$. 
rreteras. La iglesia mexicana recientemente dio reconocimiento oficial a su aparición en la pared de una estación de metro en la ciudad de México. La Virgen de Zapopan, figura móvil que normalmente circula entre las parroquias de la ciudad de Guadalajara para proteger contra las inundaciones, hace unos cinco años empezó a viajar a California, convocada por sus fieles en Los Ángeles. Como las mismas comunidades, la Virgen se autoduplicó, creando una nueva versión de sí misma para entrar en el circuito transnacional.

Estos procesos innovadores de reensamblaje, integración y continuidad pueden parecer insignificantes en el contexto de las grandes re-estructuraciones impuestas por el FMI. Pero, como señala J. K. Gibson-Graham, hay que preguntarse si parecen insignificantes porque lo son, o porque nosotros estamos predispuestos para verlos como tal ${ }^{8}$.

Acostumbrados a dar monopolio interpretativo al capitalismo, a ver desde la hegemonía, ¿será que hemos aprendido a ver otros elementos y dinámicas históricas como insignificantes? Gibson-Graham arguye que esta tendencia a reducirlo todo a lo mismo, aceptando la parálisis del desespero, es una lección que se tiene que desaprender. Trabajando a veces en contra de nuestras propias intuiciones, los analistas debemos intentar contar la historia de otra manera, cuestionar el orden obvio de lo significante y lo insignificante. Los analistas, subraya GibsonGraham, al describir el mundo también lo producimos, resaltando ciertos factores y haciendo invisibles otros. Nuestros actos de representación son ejercicios de libertad, y traen responsabilidades y consecuencias

Las nuevas prácticas de integración y reensamblaje reflejan compromisos, esfuerzos y creatividad enormes, en el ámbito individual y colectivo. El mito americano del inmigrante que busca una nueva vida olvidando sus orígenes todavía existe, pero ahora coexiste con el nuevo relato migrante cuyo proyecto es sostener el lugar de origen, a menudo a través de procesos de auto-duplicación, como el de la Virgen de Zapopan. Trabajar en el exterior para mantener el lugar natal implica, con frecuencia, una doble nacionalidad tanto en el sentido literal (cada vez más países la reconocen) como en el sentido existencial de

\footnotetext{
${ }^{8}$ GIBSON-GRAHAM, J. K. The end of capitalism (as we knew it): A feminist critique of political economy. Rutgers: Rutgers UP, 1995.
} 
una especie de desdoblamiento del yo en identidades paralelas en un lugar y en otro. Esta puede ser una experiencia a la vez fragmentadora y emancipadora.

Me parece importante subrayar otra vez la medida en que, a pesar de los imperativos económicas que motivan la migración, estas prácticas integradoras, bien subsumidas por la expresión en inglés "get it together," no son funcionales para el capitalismo, ni se pueden explicar por él. La movilización del "aquî" para mantener el "allá" no obedece, por ejemplo, a los dictados del consumismo o del individualismo ni a los valores consumistas de autorealización personal. Nuestros temores a la nostalgia, o a lo que recientemente se condena como "romanticismo," no deberían ocultarnos el hecho de que a través del planeta se están elaborando prácticas y modos de vivir que rechazan las intensas desagregaciones que sí son funcionales para el capitalismo. Junto con las vírgenes errantes, uno de los héroes actuales de este relato es el teléfono celular, tanto en las torres de Nueva York como en la sierra de Guatemala.

\section{La desmodernización}

Volvemos, para concluir, al tema de las zonas de exclusión. En los primeros años de este nuevo milenio, estamos presenciando cambios que aparecen como procesos de desmodernización. La gran narrativa del progreso da marcha atrás. Atestiguamos, por ejemplo, la vuelta "dickensiana" del trabajo infantil, el retorno de la esclavitud, el regreso de los ex-dueños coloniales como dueños de empresas en las ex-colonias. En Perú el gobierno propone deshacer la reforma agraria, devolviendo las haciendas a sus antiguos dueños. En Argentina, el colapso del país que se consideraba el más moderno y el más modernizante en toda América Latina, se registra en una serie de retornos : la economía de trueque, la multiplicación de monedas, la venta de niños, la agricultura de subsistencia, aún en contextos urbanos. En medio de la enorme crisis argentina, el periódico nos trae la noticia, con foto, de un argentino en poncho que emprende un viaje alrededor de la tierra a caballo : hasta los símbolos nacionales se desmodernizan, como si se leyera el libro de Melquíades al revés.

Una dimensión particularmente significativa de esta desmodernización ha sido la erosión de las redes totalizadoras e inclusivas que realizaban el proyecto democratizador de la modernidad. Me refiero a las redes nacionales de educación, de transporte (redes viales y ferroviarias, aerolíneas nacionales), de comunicación (telégrafo, teléfono, radio), las redes judiciales y electorales. Bajo la presión neoliberal, los estados revisan sus funciones, abandonando los roles 
redistributivos y custodiales que mantenían su carácter democrático. Con relación a las redes, dejan de mantener las ramas locales. Las redes se marchitan y, dejando de ser totalizadoras, se vuelven discontinuas o nodales. Los territorios entre los nudos se convierten en zonas de exclusión, es decir, pasan de ser incluyentes a ser no-incluyentes. En Lima puede ser más fácil importar papas desde Kansas City que desde Sicuani; más fácil hablar por celular con el primo de Bangkok que hablar por teléfono público con el primo en San Juan de Lurigancho; más fácil pedir un libro desde Miami que desde Chiclayo o Quito.

El resultado de estos procesos de desmodernización, y de la transformación de redes incluyentes en nudos excluyentes son vastas zonas de exclusión y marginalidad donde la vida se tiene que llevar de otra manera, donde la ganancia y el consumo no son lo que da sentido a la vida. En estas zonas proliferan la tristeza, el sufrimiento y el desespero, pero también se crean otros conocimientos, valores, placeres, otras narrativas, otros modos de vivir la vida, de gozarla, de darle sentido. Dos breves casos del Perú pueden servir de ejemplos. El primero es la visión de Lima captada por un extraordinario video hecho por la peruana-holandesa Heddy Honigmann en 1993, durante la agudización de la crisis económica del Perú. Titulado "Metal y melancolía," su tema son los taxistas de Lima, término que en 1993 se refería a casi todo limeño que tuviera acceso a un coche. El video capta, mejor que cualquier otra obra que conozca, la respuesta de las personas ante su expulsión de la narrativa de desarrollo que antes estaban viviendo, documentando tanto el sufrimiento y el desespero como la creatividad, la voluntad, y el valor con que enfrentaban la necesidad de vivir de otra manera y de darle sentido a la vida en circunstancias nuevas y dolorosas. Escena tras escena, el video exhibe el desarrollo creativo de nuevas prácticas materiales, los nuevos procesos de deshacer y rehacer frente a la escasez radical, la incesante labor de desatar y reatar cables (literalmente), y las prácticas semánticas, existenciales que daban sentido a la escasez y a la pérdida de esperanzas.

El segundo ejemplo es una nueva cosmología que llegué a conocer tras ingresar a un pequeño restaurante vegetariano en Cuzco, en julio de 2002. Se trata de la secta religiosa Alpha y Omega cuyos símbolos centrales son el cordero de dios y el platillo volador, y cuya doctrina se origina en mensajes telepáticos comunicados por el padre eterno a sus representantes terrestres. Estas "doctrinas para el tercer milenio" están conservadas en cuatro mil rollos celestiales que explican "el origen, causa y destino de todas las cosas conocidas y 
desconocidas," según el panfleto impreso que distribuyen. Fuertemente antimaterialista, la secta caracteriza al capitalismo como "la extraña ley del oro" y anuncia el nuevo "reinado de la verdad, la justicia, y la igualdad con cielo nuevo, tierra nueva y conocimiento nuevo". Es sólo una de docenas de nuevas formaciones filosófico-cosmológico-religiosas que surgen en las zonas de exclusión ofreciendo paradigmas de significación independientes del materialismo y de la narrativa fracasada del desarrollo.

La incapacidad del neoliberalismo para generar pertenencia, colectividad y un sentido creíble de futuro produce, entre otras cosas, enormes crisis de existencia y de significados que están siendo vividas por los no consumistas y los consumistas del mundo en formas que la ideología neoliberal no puede predecir ni controlar. Los monstruos chupadores, los riñones robados y los cerebros recuperados, las vírgenes móviles, los rollos telepáticos y los discos pirateados son los síntomas de estas crisis, y también los agentes inescrutables de un futuro cuyos contornos desconocemos. 